\title{
Rehabilitation and strengthening of concrete structures using Ultra-High Performance Fibre Reinforced Concrete
}

\author{
E. Brühwiler \\ Ecole Polytechnique Fédérale de Lausanne (EPFL), Lausanne, Switzerland
}

\begin{abstract}
An original concept is presented for the durable rehabilitation and strengthening of concrete structures. The main idea is to use Ultra-High Performance Fibre Reinforced Concrete (UHPFRC) complemented with steel reinforcing bars to "harden" and strengthen those zones of the structure that are exposed to severe environmental influences and high mechanical loading. This concept combines efficiently protection and resistance properties of UHPFRC and significantly improves the structural performance of the rehabilitated concrete structure in terms of durability. The concept has been validated by means of field applications demonstrating that the technology of UHPFRC is mature for cast in-situ and prefabrication using standard equipment for concrete manufacturing. This novel technology is a step forward towards more sustainable structures.
\end{abstract}

\section{INTRODUCTION}

Reinforced concrete structures show excellent performance in terms of structural behaviour and durability except for those zones that are exposed to severe environmental influences and high mechanical loading. Rehabilitation of deteriorated concrete structures is a heavy burden from the socio-economic viewpoint since it leads to significant user costs. As a consequence, novel concepts for the rehabilitation of concrete structures must be developed. Sustainable concrete structures of the future will be those requiring just minimum interventions of only preventive maintenance with no or only little service disruptions.

Over the last 10 years, considerable efforts to improve the behaviour of cementitious materials by incorporating fibres have led to the emergence of Ultra-High Performance Fibre Reinforced Concretes (UHPFRC). These novel building materials provide the structural engineer with an unique combination of (1) extremely low permeability which prevents the ingress of detrimental substances such as water and chlorides (Charron et al. 2006) and (2) very high strength, i.e., compressive strength higher than $150 \mathrm{MPa}$, tensile strength higher than $10 \mathrm{MPa}$ and with considerable tensile strain hardening and softening behaviour (Denarié \& Brühwiler 2011).

Consequently, UHPFRC have improved resistance against severe environmental influences and high mechanical loading thus providing a potential to significantly improve structural resistance and durability to concrete structures.
This keynote paper presents an original concept for the rehabilitation and strengthening of concrete structures. The concept is described and some scientific background regarding the structural behaviour of RC elements strengthened with UHPFRC is given. Finally, this novel technology is validated by means of applications.

This paper summarizes more than 12 years of intensive research and development of a novel technology to improve concrete structures.

\section{CONCEPTUAL IDEA}

The basic conceptual idea is to use UHPFRC only in those zones of the structure where the outstanding UHPFRC properties in terms of durability and strength are fully exploited; i.e. UHPFRC is used to "harden" the zones where the structure is exposed to severe environmental conditions (f.ex., deicing salts, marine environment) and high mechanical loading (f.ex. impact, concentrated loads, fatigue). All other parts of the structure remain in conventional structural concrete as these parts are subjected to relatively moderate exposure.

This concept (which is also applicable to new construction) necessarily leads to composite structural elements combining conventional reinforced concrete and UHPFRC.

The combination of the UHPFRC protective and load carrying properties with the mechanical properties of steel reinforcement bars (denominated reinforced UHPFRC or R-UHPFRC) 
provides a simple and efficient way of increasing the stiffness and load-carrying capacity while keeping compact cross sections (Fig. 1).

Depending on the structural and material properties of the composite system, more or less pronounced built-in tensile stresses are induced in the UHPFRC layer due to restrained deformations at early age. This stress state needs to be analysed and evaluated but is usually resisted by the UHPFRC without crack formation (Oesterlee et al. 2008).

The original conceptual idea (developed in 1999) has been investigated by means of extensive research activities aimed at characterizing UHPFRC materials and their properties as well as the structural behaviour of R-UHPFRC-RC composite structural members, combining material and structural engineering sciences. The concept is well-suited for bridges, buildings, galleries, tunnels and retaining walls.

\section{COMPOSITE R-UHPFRC-RC SECTIONS}

\subsection{Mix design and fresh UHPFRC properties}

UHPFRC mixes typically contain 700 to $1^{\prime} 000 \mathrm{~kg} / \mathrm{m}^{3}$ cement as well as microsilica and fine quartz sand with a maximum grain size of $0.5 \mathrm{~mm}$. The water/ binder ratio is 0.13 to 0.17 . These components are mixed using a superplasticiser to obtain an ultracompact matrix. More recently limestone filler was used to replace a significant amount of cement and to improve workability leading to more economic and environmentally friendly UHPFRCs (Denarié 2009). This matrix is strengthened by straight steel fibres typically of 10 to $15 \mathrm{~mm}$ length and with an aspect ratio of 50 to 80 , often with a dosage of at least $3 \%$ in volume.

UHPFRCs have excellent rheological properties in the fresh state allowing for easy casting of the self-compacting fresh material with conventional concreting equipment on the construction site and in the prefabrication plant.

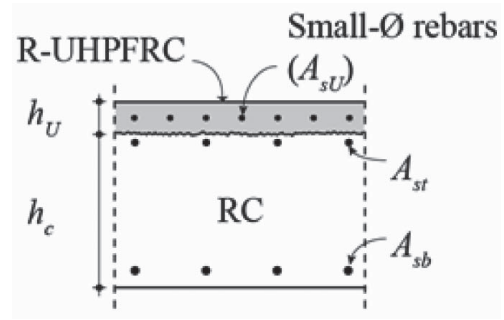

Figure 1. Basic configuration of composite structural elements combining R-UHPFRC and conventional reinforced concrete.

\subsection{Tensile behaviour of UHPFRC and $R$-UHPFRC}

\subsubsection{Plain UHPFRC}

As illustrated in Figure 2, the uniaxial tensile behaviour of UHPFRC is divided into three phases:

First, the material is elastic up to initiation of microcracking of the matrix. Point $\mathrm{A}$ is denoted as elastic limit strength $f_{U t, e l}$ with typical values of 7 to $11 \mathrm{MPa}$ for currently used UHPFRCs.

Second, it goes into a phase of strain hardening with multiple (non-visible) microcracking of the matrix and fibre activation. The material still behaves like a continuum. Significant strain hardening behaviour is only obtained with a fibre content of at least 3\% in volume. Strain hardening domain may reach to strains of $\varepsilon_{U t, u}=2$ to $5 \%$ where the tensile strength $f_{U t, u}$ is reached with typical values ranging from 9 to $15 \mathrm{MPa}$.

Third, upon the formation of a discrete macrocrack at ultimate resistance, the phase of strain softening begins with maximum crack openings reaching about half of the fibre length, i.e., 5 to $8 \mathrm{~mm}$.

The tensile hardening and softening behaviour of UHPFRC depends on the random orientation and distribution of the straight steel fibres with a slenderness ratio of typically of 50 to 100 (Wuest 2007, Oesterlee 2010).

The fractured surface of a UHPFRC specimen after a tensile test shows numerous steel fibres, pulled out from the matrix. The corresponding work of pull-out explains the relatively high specific fracture energy $G_{F}$ of UHPFRC (typically ranging from 20 to $30 \mathrm{~kJ} / \mathrm{m}^{2}$ ). A significant part of the work of fracture of UHPFRC is dissipated in the bulk of the material, during the strain hardening phase.

The mechanical response of fibrous composites such as UHPFRC is much application dependent. Anisotropy effects can be induced by the casting procedure of the materials or the width and shape of the moulds. These effects have to be considered for the analysis of test results and for design. Adding reinforcing bars to the UHPFRC reduces these anisotropy effects.
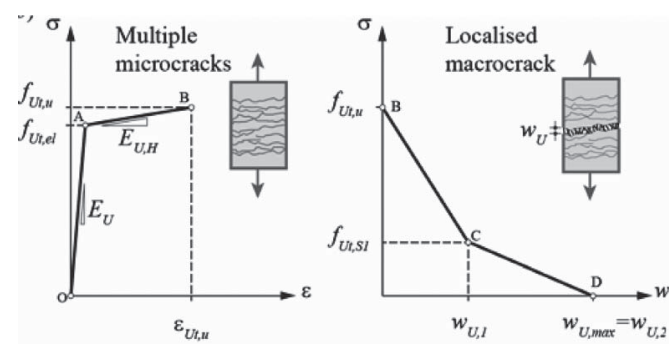

Figure 2. Tensile behaviour of UHPFRC: Material laws. 


\subsubsection{R-UHPFRC}

Scatter in the tensile behaviour of plain UHPFRC is one reason to complement UHPFRC by steel reinforcement bars. The small diameter steel reinforcing bars (arranged with small spacings) provide in-plane continuity to the UHPFRC layer and ensure its monolithic action with the RC element in flexural members (Habel 2004, Oesterlee 2010).

The rebars increase not only the resistance but also improve the deformation capacity and strain hardening behaviour of UHPFRC. The reinforcing bars enhance the apparent UHPFRC tensile behaviour.

The global tensile behaviour of R-UHPFRC can be described by the linear superposition of the steel and the UHPFRC tensile behaviour (Fig. 3). The localization of the deformation in one macrocrack occurs at the start of yielding of the reinforcing steel. This is independent on the steel grade of the reinforcement. The magnitude of strain hardening of UHPFRC falls into the range of the yield strain of steel rebars. This property opens up the combination of UHPFRC with reinforcement bars with high yield strength (700 MPa or above).

The use of reinforcing bars with different steel grades and surface characteristics, namely ribbed and smooth bars, showed that the pre-peak behaviour is independent of the bond strength and that the crack spacing is dominated by the fibre reinforcement. Relative to ribbed reinforcing bars, smooth rebars have lower bond strength, allow for larger post-peak deformations and avoid localised stress concentration in the softening UHPFRC macrocrack.

\subsection{Structural response of $R-U H P F R C-R C$ composite beams}

\subsubsection{Behaviour due to bending}

When in tension, the R-UHPFRC layer principally acts as an added flexural reinforcement for the RC

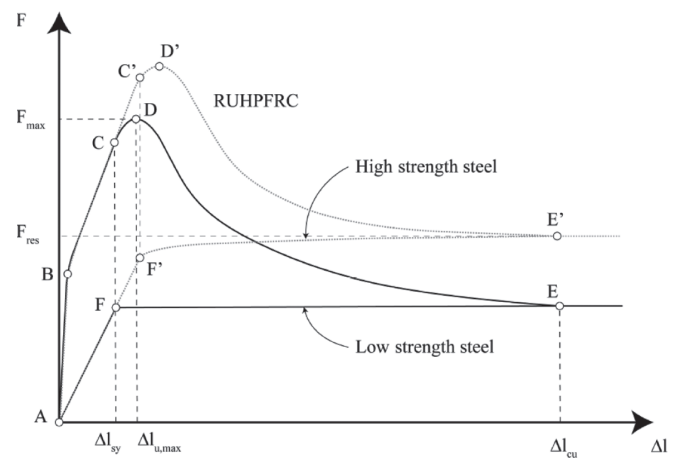

Figure 3. Characteristic tensile behaviour of R-UHPFRC. element. Both steel rebars and UHPFRC contribute to the resistance.

The strengthening of reinforced concrete beams with an R-UHPFRC layer is characterised by a significant increase of the ultimate resistance and stiffness (depending on the type and strength of the steel reinforcement) (Habel 2004, Oesterlee 2010).

The bond between UHPFRC and concrete obtained after preparing the concrete support surface using high pressure water jet or sand blasting, is sufficient to avoid debonding. In fact, in all fracture tests there was no debonding along the interface zone beyond ultimate resistance and significantly into the post-peak domain. (Since there is no slip between the two layers, shear connectors would not be effective and can thus be avoided).

The plastic post-peak rotation capacity of strengthened RC beams is reduced by the UHPFRC layer. Through the choice of the appropriate UHPFRC reinforcement the reduction of plastic rotation capacity can be controlled. Smooth bars bring the least reduction, ribbed bars the highest. The use of smooth high yield strength reinforcing bars in the UHPFRC layer offers a high strengthening effect while the post-peak rotation capacity remains high.

The characteristic structural behaviour of composite sections subjected to bending can be described and the ultimate moment be calculated using the conventional model for $\mathrm{RC}$ with an extension to account for the R-UHPFRC layer (Fig. 4) (Habel et al. 2006, Oesterlee 2010).

When in compression, the R-UHPFRC layer acts as a compression chord but the high UHPFRC compressive strength of about $200 \mathrm{MPa}$ cannot be exploited in R-UHPFRC-RC members.

\subsubsection{Behaviour due to combined bending and shear}

When subjected to combined bending and shear, R-UHPFRC-RC members are susceptible to Intermediate-Crack-induced debonding (ICD) (Fig. 5) that softens the connection between the two elements (Noshiravani 2012). The relative vertical movement of the RC segments separated by inclined flexure-shear cracks in the RC generates prying stresses on the R-UHPFRC layer. These stresses are resisted by the R-UHPFRC tensile element bending in double curvature.

Working against the R-UHPFRC, the opening and full development of a flexural-shear crack in the RC element leads to a flexure-shear collapse mechanism of the composite member. The R-UHPFRC element contributes to the member resistance before and after formation of the flexure-shear collapse mechanism.

The ultimate resistance of R-UHPFRC-RC beams and slabs subjected to combined bending 


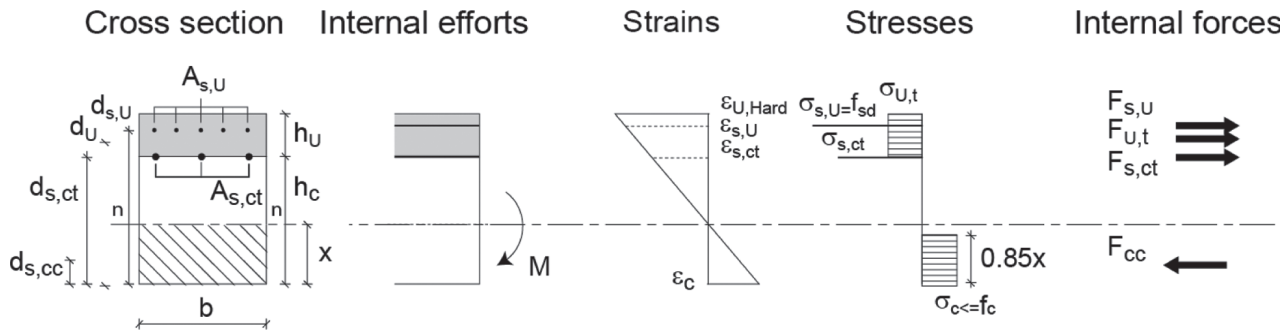

Figure 4. Determination of ultimate moment of R-UHPFRC.

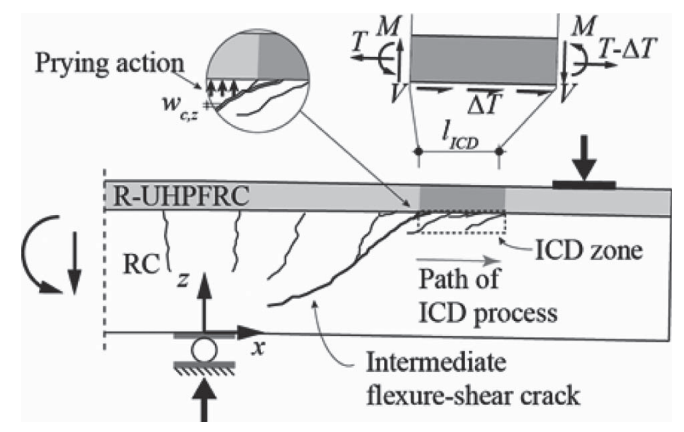

Figure 5. Intermediate-Crack-induced Debonding (ICD) in R-UHPFRC-RC elements subjected to combined bending and shear.

and shear depends on the shear span-depth ratio (a/d), the ratio of shear reinforcement (stirrups) in the $\mathrm{RC}$ element, the longitudinal reinforcement, namely the steel rebars and the UHPFRC section, and finally the bond characteristics of each reinforcement, including that of the UHPFRC layer which is influenced by the ICD zone.

The contribution of the tensile R-UHPFRC element is twofold: First, the element resists the out-of-plane prying stresses by bending in double curvature; second, by acting as an external tensile reinforcement, the element controls the width of cracks in concrete, thus increasing the contribution of the latter to the shear resistance. It was estimated that the R-UHPFRC element carries 30\% of the total shear resistance.

Both mechanisms are inversely related to the length of the ICD zone between the RC and R-UHPFRC elements. While the former mechanism contributes to the shear resistance of the layer after a flexure-shear failure, the latter is replaced by the tensile membrane action of the R-UHPFRC reinforcement. Analogous to the longitudinal tensile rebars, the vertical component of the tensile force in the deformed R-UHPFRC element contributes to the shear resistance of the member. The post-peak flexure-shear failure mechanism is of interest in the design of structures that require structural redundancy and the ability for load redistribution following a local failure, thus preventing a progressive collapse.

Models were developed to predict the ultimate resistance and the pre-peak deformation capacity of the beams (Noshiravani 2012).

\subsubsection{Fatigue behaviour}

Experimental campaign was performed on plain UHPFRC and R-UHPFRC specimens (Fig. 7 left) as well as R-UHPFRC - RC composite beams.

The tensile fatigue behaviour of plain UHPFRC under constant amplitude fatigue cycles up to 10 million cycles were conducted with the objective to determine the endurance limit of UHPFRC that was supposed to exist for this material. These fatigue tests revealed that an endurance limit exists in all three domains of UHPFRC tensile behaviour (i.e., elastic, hardening and softening behaviour) at S-ratios ranging from 0.70 to 0.45 with $\mathrm{S}$ being the ratio of the maximum fatigue stress to the elastic limit strength of UHPFRC.

Rather large variation in local specimen deformations were measured during the tests which indicates significant stress and deformation redistribution capacity of the UHPFRC bulk material enhancing the fatigue behaviour.

The fatigue fracture surface of UHPFRC showed features of fatigue fracture surfaces known from steel, i.e. fatigue crack propagation is identified by a smooth surface while final fracture leads to rather rough surface. Various fatigue damaging mechanisms due to fretting and grinding as well as tribocorrosion were identified.

The fatigue tests on R-UHPFRC showed internal stress distribution. Measured growth of the deformation of R-UHPFRC was attributed to stiffness degradation of UHPFRC caused by microcracking in the hardening domain. Fatigue fracture process of R-UHPFRC specimens was finally determined by fatigue fracture of steel rebars (Fig. 7 right).

The results from bending fatigue tests on R-UHPFRC-RC beams (Fig. 8) revealed the existence of a fatigue limit at 10 million cycles at 

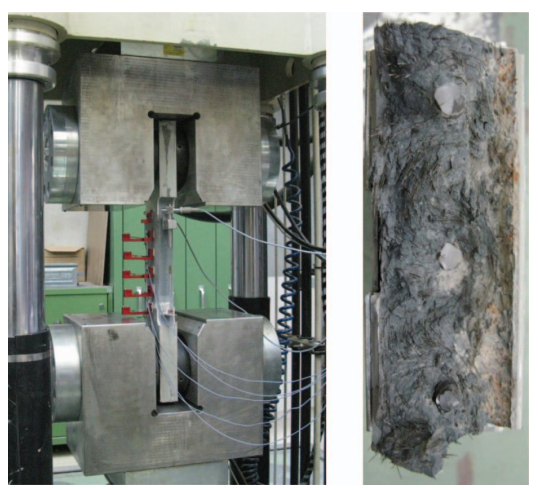

Figure 7. Tensile fatigue test set-up on plain and R-UHPFRC; fracture surface of R-UHPFRC (dimensions: $40 \times 110 \mathrm{~mm}^{2}$ ).

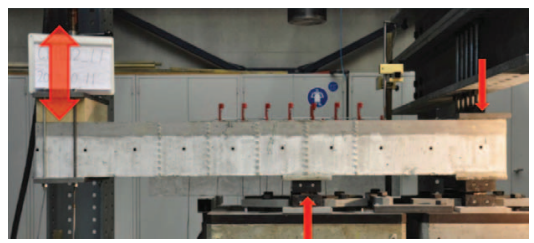

Figure 8. Bending fatigue test set-up on R-UHPFRCRC composite beams (beam length: $1900 \mathrm{~mm}$, depth: $220 \mathrm{~mm})$.

a solicitation level of about $50 \%$ of the ultimate static strength of the R-UHPFRC-RC beam. At fatigue solicitation levels above this value, the fatigue life was rather short and no relevant fatigue strength seems to exist.

Fatigue fracture process of R-UHPFRC-RC beams was determined by fatigue fracture of steel rebars in the R-UHPFRC layer.

Consequently, fatigue design rules for $\mathrm{R}$ UHPFRC - RC members under bending fatigue need to account for steel rebar and UHPFRC fatigue resistances.

\section{APPLICATIONS}

\subsection{Introduction}

Since 2004, UHPFRC is applied in Switzerland (and in one case in Slovenia following the same concept (Šajna et al. 2012)) on existing reinforced concrete bridge deck slabs as thin watertight overlays (in replacement of currently used waterproofing membranes) as well as reinforcement layer in R-UHPFRC providing both protection and load bearing functions for bridge elements and slabs in buildings without increasing the dead load of the structure.
Specific parts of reinforced concrete structures such as crash barrier walls on highway bridges, bridge piers and retaining walls suffer from severe exposure to concrete aggressive substances such as de-icing salts and impact like action. Such elements usually show insufficient durability when built in conventional reinforced concrete. Again, UHPFRC is suitable to establish the required durability and mechanical performance of such structural elements.

\subsection{Waterproofing of bridge deck slabs}

The first field application of UHPFRC in 2004 was for the rehabilitation and widening of a short span road bridge with busy traffic (Denarié \& Brühwiler 2006, SAMARIS 2005). The entire deck surface of the bridge was rehabilitated in three steps (Fig. 9).

Firstly, the downstream curb was replaced by a new prefabricated UHPFRC curb on a new reinforced concrete beam which was necessary for the widening. Secondly, the chloride contaminated concrete of the upper surface of the bridge deck was replaced by $30 \mathrm{~mm}$ of UHPFRC in two consecutive steps such that one traffic lane could be maintained open. Thirdly, the concrete surface of the upstream curb was replaced with $30 \mathrm{~mm}$ of UHPFRC.

The fresh self-compacting UHPFRC material was prepared at a local concrete prefabrication plant with a standard mixer, brought to the site by a truck and then poured on the deck surface prepared by high pressure water jetting (Fig. 10). The UHPFRC was easy to produce and place with

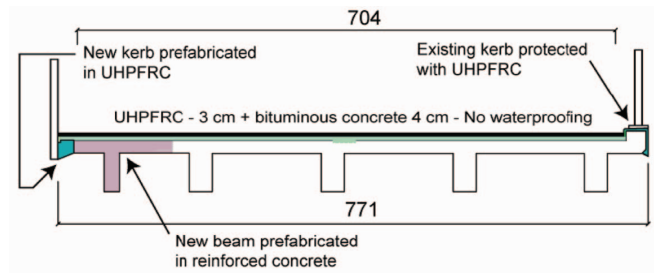

Figure 9. Bridge cross section after rehabilitation (dimensions in $\mathrm{cm}$ )

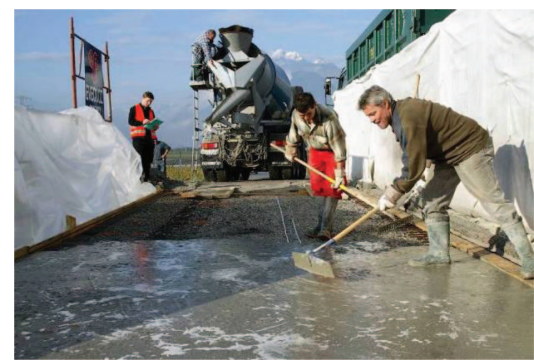

Figure 10. UHPFRC casting and handling of UHPFRC using simple tools. 
standard tools and very robust and tolerant to the unavoidable particular site conditions.

The bituminous pavement was applied on a bituminous emulsion placed on the UHPFRC surfaces after 8 days of moist curing, and the corresponding lane was reopened to traffic the next day. The bridge was fully reopened to traffic one month after the beginning of the construction work.

The protective function of the UHPFRC layer was verified by air permeability tests. Material tests confirmed the expected mechanical properties of UHPFRC.

Several more applications (Fig. 11) following the same principle have been conducted under various weather conditions and construction site constraints (Denarié et al. 2011). Fresh UHPFRC has also been mixed on the construction site and by optimizing additives maximum slopes of up to $10 \%$ could be cast with this self-compacting material.

\subsection{Protection of vertical surfaces}

A layer of UHPFRC has been applied to the concrete crash barrier walls of a highway bridge covering the areas subjected to splash exposure (Fig. 12). The main design requirement was to obtain long-term durable crash barrier walls since traffic interruption for future rehabilitation interventions are prohibitive due to the very high traffic volume on this highway. Long-term durability is obtained when transverse macro-cracks in the UHPFRC layer are absent and the permeability of

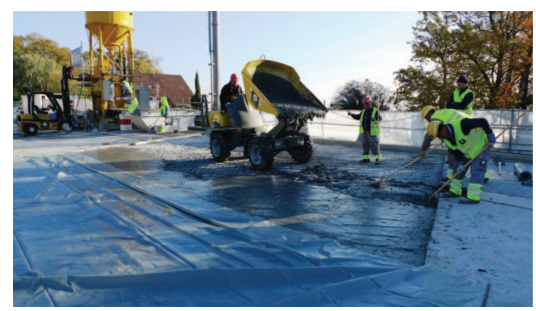

Figure 11. On-site production and casting of UHPFRC.

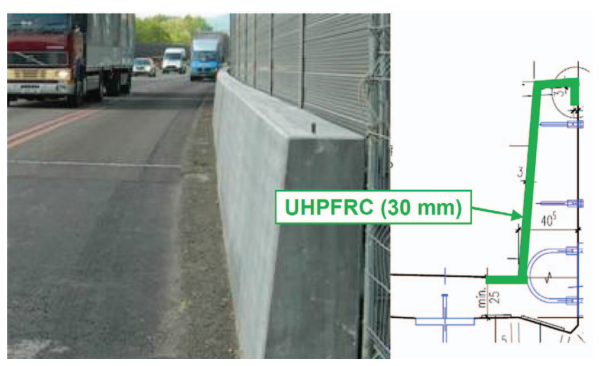

Figure 12. Typical cross section of the crash barrier wall and view after rehabilitation.
UHPFRC layer to ingress of water and chloride ions is extremely low.

The rheological properties of UHPFRC were adapted for easy pouring into the $30 \mathrm{~mm}$ wide formwork to fill a height of $1.20 \mathrm{~m}$.

Due to restrained early age deformation of the UHPFRC (mostly due to thermal and autogenous shrinkage) bonded to the existing reinforced concrete wall, an internal stress state is built up in the composite element including, in particular, tensile stresses in the UHPFRC layer. These tensile stresses, which can cause crack formation, and the capacity of the UHPFRC to resist to these stresses were investigated by means of numerical analyses prior to the intervention (Oesterlee et al. 2007). Four months after application no crack could be found confirming the predictions made by the numerical simulations.

A next application consisted in fabricating $40 \mathrm{~mm}$ thick UHPFRC shell elements to form an outer protection shield for an existing 40 year-old reinforced concrete bridge pier which was severely damaged by chloride induced rebar corrosion. The joints between the different UHPFRC shell elements were glued using an epoxy resin. This pier is located in the middle of a busy highway making it virtually not accessible for future maintenance interventions.

\subsection{Strengthening of bridge deck slabs and slabs in buildings}

Example 1: The deck slab of a more than 70 year old reinforced concrete bridge of high cultural value had to be rehabilitated and strengthened to accommodate for future traffic demands of a village in a mountainous area.

The intervention consisted in casting a layer of R-UHPFRC on top of the deck slab with the objective to improve the durability and to restore the structural safety (Fig. 13). Gravel was dispersed on the fresh UHPFRC such as to obtain the required roughness of the surface fit for road traffic.

Example 2: The 50 year-old drivable reinforced concrete floor of a fire brigade building had insufficient load carrying capacity in view of heavier future fire engines. The concept to increase the load carrying capacity of the existing slab of $720 \mathrm{~m}^{2}$ area was to pour a $40 \mathrm{~mm}$ thick UHPFRC layer on top of the existing RC slab, as a replacement of the existing cementitious non-load carrying overlay (Fig. 14).

The UHPFRC layer leads to a thicker load carrying slab which provides a better distribution of local wheel loads, an increase in static height and a high strength material to resist both compression or tension stresses.

The use of the UHPFRC solution turned out to be very economic (compared to the conventional 


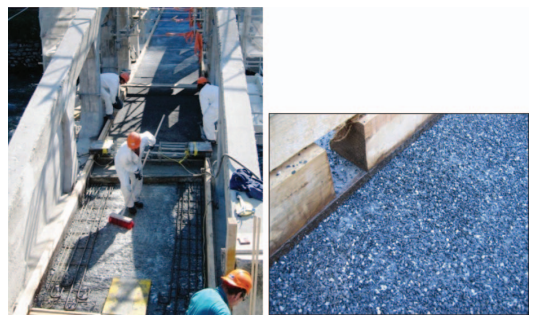

Figure 13. Rehabilitation and strengthening of a bridge deck slab with reinforced UHPFRC; drivable UHPFRC surface.
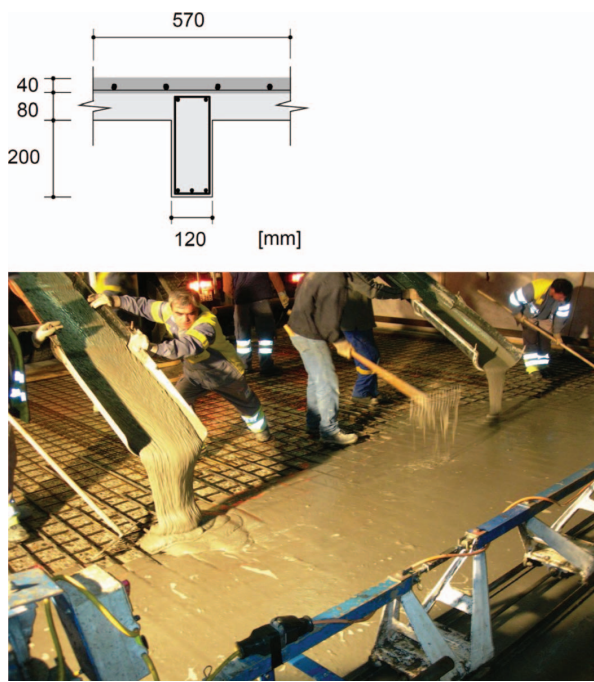

Figure 14. Cross section (dimensions in $\mathrm{cm}$ ) with $\mathrm{R}$-UHPFRC layer (in dark grey) and view of UHPFRC casting.

solution of slab demolition and reconstruction). Additionally, the utilization of the fire workers building was only slightly restricted during the intervention and thus user costs could be kept minimal.

Example 3: Massive RC slab bridge built in 1963 with six supporting columns was improved in autumn 2011 by applying UHPFRC and R-UHPFRC to its whole deck surface. The bridge is part of a road with heavy traffic (Fig. 15). Load bearing capacity of the bridge was found to be insufficient for todays and future vehicles. Besides, its deck slab was deteriorated due to chloride induced rebar corrosion

UHPFRC layer of $25 \mathrm{~mm}$ thickness was cast for water-proofing of the deck, and the area above the columns were strengthened by a $65 \mathrm{~mm}$-thick R-UHPFRC layer to increase bending and punching shear resistance (Fig. 16). The UHPFRC mix contained cement, limestone filler, silica fume, quartz sand, $4.5 \%$ steel fibres by volume and superplasticiser. The UHPFRC material was prepared on site and about 300 litres were mixed per batch. RC top surface of 20 to $40 \mathrm{~mm}$ depth was first treated with high pressure water jet. UHPFRC was then cast with standard and simple tools (Fig. 16).

Bituminous pavement was finally applied on a bituminous emulsion on the UHPFRC surface after more than three days of curing. Traffic in both directions was kept in service on one traffic lane during the works.

\subsection{Economic aspects}

The relatively high material cost imposes to use UHPFRCs only where maximum benefit of their outstanding mechanical properties can be taken. Obviously, the more requirements (regarding durability, structural/fatigue safety, and functionality) are fulfilled with one UHPFRC layer, the more efficient and economical is the technology.

Analysis of construction costs alone showed that the rehabilitation realized with UHPFRC was in most cases not more expensive and in some cases significantly less expensive than conventional methods (which provide however lower quality in terms of durability and life-cycle costs).

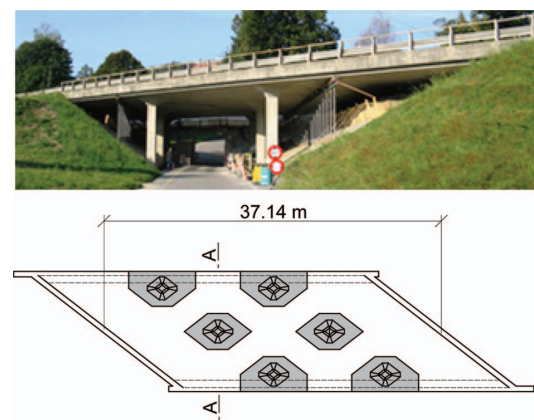

Figure 15. Massive slab bridge strengthened using R-UHPFRC over piers (dark areas).

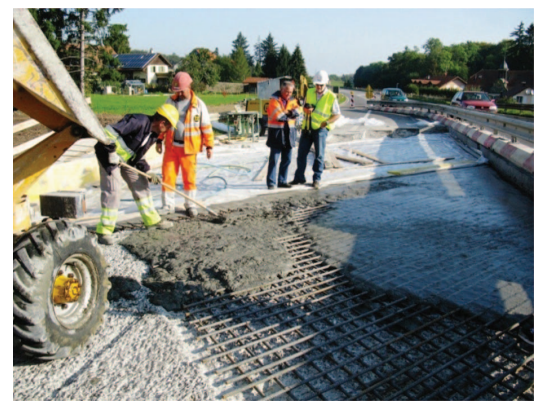

Figure 16. UHPFRC casting for R-UHPFRC strengthened zone over a pier. 
In addition, the UHPFRC technology allows for significant reductions in the duration of construction site reducing thus user costs. Also, it provides significant gains in terms of long term durability and reduction of traffic disruptions (and subsequent user costs) due to multiple interventions (required in the case of conventional approaches).

\section{CONCLUSIONS}

An original concept using Ultra-High Performance Fibre Reinforced Concrete (UHPFRC) for the rehabilitation and strengthening of concrete structures has been developed and validated by means of site applications.

The conceptual idea combines efficiently the protection and resistance properties of UHPFRC with conventional structural concrete. The rehabilitated structures have significantly improved structural resistance and durability.

More than 10 applications of the concept under site conditions demonstrate the potential of this novel technology.

The technology of UHPFRC is mature for cast in-situ and prefabrication using standard equipment for concrete manufacturing.

This original concept should also be applied for the construction of durable new reinforced concrete structures (Brühwiler et al. 2007).

\section{ACKNOWLEDGEMENTS}

The support of the Swiss National Science Fund, The Swiss Secretary of Education and Research, The Committee of Technology and Innovation, Cemsuisse, Holcim, Swiss Steel AG and the Swiss Federal Roads Office is gratefully acknowledged. The applications were possible thanks to several Road and Railway Administrations in Switzerland.

The author gratefully acknowledges the contributions of current and former doctoral researchers and coworkers of his UHPFRC team at MCSEPFL, in particular Dr Emmanuel Denarié.

\section{REFERENCES}

This paper summarizes research activities of MCS's UHPFRC group at EPFL, and it is referred to own articles only. References to contributions by other research groups and researchers can be found in the listed papers:

Brühwiler, E., Fehling, E., Bunje, K. \& Pelke, E. 2007. Design of an innovative composite road bridge combining reinforced concrete with Ultra-High Performance Fibre Reinforced Concrete. Proceedings, IABSE
Symposium "Improving Infrastructure Worldwide", Weimar, September 2007.

Charron, J.-P., Denarié, E. \& Brühwiler, E. 2006. Permeability of Ultra High Performance Fiber Reinforced Concretes (UHPFRC) under high stresses, Materials and Structures, 40(3): 269-277.

Denarié, E. \& Brühwiler, E. 2006. Structural rehabilitations with Ultra High Performance Fibre Reinforced Concretes, International Journal for Restoration of Buildings and Monuments, Aedificatio Publishers Freiburg Germany, 12(5+6): 453-467.

Denarié E. 2009. Recommendations for the tailoring of UHPFRC recipes for rehabilitation, Deliverable ARCHES D06, http://arches.fehrl.org.

Denarié E. \& Brühwiler E. 2011. Strain Hardening of Ultra-high Performance Fibre Reinforced Concrete: Deformability versus Strength Optimization, International Journal for Restoration of Buildings and Monuments, Aedificatio Publishers Freiburg Germany, 12(6).

Denarié E., Kazemi-Kamyab H., Brühwiler E., Haddad B. \& Nendaz S. 2011. Béton fibré ultra performant pour la main-tenance, un nouvel élan. Tracés 12: 20-23.

Habel, K. 2004. Structural behaviour of elements combining Ultra-High Performance Fibre Reinforced Concretes (UHPFRC) and Reinforced Concrete. Doctoral Thesis No 3036, Ecole Polytechnique Fédérale de Lausanne (EPFL).

Habel, K., Denarié, E.\& Brühwiler, E. 2006. Structural response of elements combining Ultra-High Performance Fiber Reinforced Concretes (UHPFRC) and reinforced concrete, ASCE Structural Journal, November (2006): 1793-1800.

Noshiravani, T. 2012. Structural response of R-UHPFRC - RC composite members subjected to combined bending and shear, Doctoral Thesis No 5246, Ecole Polytechnique Fédérale de Lausanne (EPFL).

Oesterlee, C., Denarié, E. \& Brühwiler, E. 2007. In-situ casting of UHPFRC protection layer on crash barrier walls. Proceedings, Advances in Construction Materials-Symposium in honour of Hans W. Reinhardt, July 2007, University of Stuttgart, Germany.

Oesterlee, C., Sadouki, H.\& Brühwiler, E. 2008. Structural analysis of a composite bridge girder combining UHPFRC and reinforced concrete, Proceedings, UHPC-2008: The Second International Symposium on Ultra High Performance Concrete, Kassel, Germany.

Oesterlee, C. 2010. Structural response of reinforced UHPFRC and RC composite members, Doctoral Thesis No 4848, Ecole Polytechnique Fédérale de Lausanne (EPFL).

Šajna, A., Denarié, E. \& Bras, V. 2012, Assessment of a UHPFRC based bridge rehabilitation in Slovenia, two years after application, Proceedings, HIPERMAT Conference, Kassel.

SAMARIS 2005. Report D22, Full scale application of UHPFRC for the rehabilitation of bridges - from the lab to the field, European project 5th FWP/SAMARIS - Sustainable and Advanced Materials for Road Infrastructures-WP 14: HPFRCC, http://samaris.zag.si/.

Wuest J. 2007. Structural behaviour in tension of UltraHigh Performance Fibre Reinforced Concrete in composite ele-ments. Doctoral Thesis No. 3987. Ecole Polytechnique Fé-dérale de Lausanne (EPFL). (in French). 